\title{
Multilevel Analysis of Dengue Hemorrhagic Fever in Bantul Regency
}

\author{
Nurkhairani'), Setyo Sri Rahardjo²), Bhisma Murti' \\ 1)Masters Program in Public Health, Universitas Sebelas Maret \\ ${ }^{2)}$ Faculty of Medicine, Universitas Sebelas Maret
}

Background: Dengue Hemorrhagic Fever (DHF) is one of the main vector-borne diseases infecting humans. It remains a major public health problem in tropical and sub-tropical regions around the world. The poor physical and social environment are the leading cause of the increasing incidence of DHF. This study aimed to determine the effect of the physical and social environment on dengue incidence using multilevel analysis.

Subjects and Method: This was an analytic a case-control study conducted in Bantul, Yogyakarta, Indonesia, from November to December 2018. A total of 250 study subjects were selected using the fix disease sampling method. The dependent variable was the incidence of DHF. The independent variables were Maya Index (MI), Density Figure (DF), household crowding, knowledge, mosquito nests eradication, and use of mosquito repellent. The data were collected using a questionnaire. The data were analyzed by using multilevel multiple logistic regression with Stata 13.

Results: The incidence of dengue fever was increased with high Maya index $(\mathrm{OR}=5.04$; 95\% $\mathrm{CI}=2.38$ to $10.67 ; \mathrm{p}<0.001)$, high density figure $(\mathrm{OR}=4.01 ; 95 \% \mathrm{CI}=1.90$ to $8.44 ; \mathrm{p}$
<0.001), high household crowding $(\mathrm{OR}=1.90$; $95 \% \mathrm{CI}=0.91$ to $3.95 ; \mathrm{p}=0.870$ ), low knowledge $(\mathrm{OR}=2.94 ; 95 \% \mathrm{CI}=1.41$ to $6.12 ; \mathrm{p}=$ 0.004), poor mosquito nests eradication behavior $(\mathrm{OR}=3.09 ; 95 \% \mathrm{CI}=1.47$ to $6.49 ; \mathrm{p}=$ o.003), did not use insect repellent $(\mathrm{OR}=3.06$; $95 \% \mathrm{CI}=0.01$ to $0.10 ; \mathrm{p}<0.001)$. Village strata had contextual effect toward the incidence of DHF with Intra-Class Correlation (ICC) by $17.34 \%$.

Conclusion: Maya Index, density figure, household crowding, knowledge, mosquito nests eradication behavior, and the use of mosquito repellents affect the incidence of DHF. Village strata have a contextual effect on DHF incidence.

Keywords: DHF, Maya Index, density figure, occupancy density, knowledge, mosquito nests eradication

\section{Correspondence:}

Nurkhairani. Masters Program in Public Health, Universitas Sebelas Maret. Jl. Ir. Sutami 36 A, Surakarta, Indonesia. Email: anachristi19@gmail.com. Mobile: +6285229185896.

Cite this as:

Nurkhairani, Rahardjo SS, Murti B (2021). Multilevel Analysis of Dengue Hemorrhagic Fever in Bantul Regency. J Matern Child Health. 06(02): 197-205. https://doi.org/10.26911/thejmch.2021.06.02.07.

cc (i) (2) Journal of Maternal and Child Health is licensed under a Creative Commons EY NC SA Attribution-NonCommercial-ShareAlike 4.0 International License.

\section{BACKGROUND}

Dengue Hemorrhagic Fever (DHF) is one of the main vector-borne diseases that infect humans. It remains a major public health problem in tropical and sub-tropical regions worldwide (Huang et al., 2017; WHO, 2012). Aedes aegypti and Aedes abopictus mosquitoes transmit the disease as the main vector carrying the Dengue virus.

There are 4 serotypes (DEN-1, DEN2, DEN-3, and DEN-4) of dengue vectors (Brady et al., 2012; Gubler, 1998). Dengue hemorrhagic fever was widespread throughout the tropics in the $18^{\text {th }}$ and $19^{\text {th }}$ cen- 
turies when the shipping industry and trade developed (Gubler, 1998).

In 2012, DHF was ranked the highest as a mosquito vector-borne disease in the world (WHO, 2012). DHF carries the burden of health problems in endemic countries that reach 112 countries worldwide, and about $75 \%$ of this number were in the Asia Pacific region (Sayavong et al., 2015; Vikram et al., 2016; WHO, 2012).

The health, social, and economic burdens experienced by endemic areas are very significant due to dengue disease, both a burden on patients and the government (Guzman and Harris, 2015; WHO, 2009) In America, an average of 2.1 billion dollars was spent on handling dengue fever did not include the vector control budget. Meanwhile, in Southeast Asia, the estimation of USD 950 million had been lost due to 5,906 deaths caused by dengue fever and an economic burden (Guzman and Harris, 2015).

Based on a World Health Organization (WHO) report, Indonesia ranked second most DHF patients country after Brazil with an average number of 129,435 cases from 2004 to 2010 (WHO, 2012). In 2016, there were 204,171 cases with 1,598 deaths in Indonesia (Ministry of Health, 2017). It showed an increasing number from 2015 by 129,650 cases with 1,071 deaths. In 2016, the incidence rate (IR) or DHF morbidity rate also increased from the previous year, 50.75 to 78.85 per 100,000 population. However, the CFR decreased from $0.83 \%$ in 2015 to 0.78 in 2016 (Ministry of Health, 2017).

Yogyakarta Special Region was one of the five provinces with the highest DHF morbidity rate of 167.89 per 1 ,000. Bantul Regency remained the region with the highest number of DHF cases in DIY until 2016, with 188 cases. The incidence rate (IR) of DHF in Bantul Regency increased from $1.48 \%(1,441$ cases $)$ in 2016 to $2.51 \%(2,442$ cases) in 2015. A map of the distribution of cases in Bantul Regency showed that DHF occurred in all sub-districts.

The determinant factors of increase in DHF cases had been proven in several previous studies. The epidemiological triangle concept certainly also applies to the incidence of DHF. Patient factors (host), disease (agent), and environment (environment) are three important parts in the spread of dengue and continue to be studied to overcome the disease.

The increasing number of DHF cases in Bantul Regency from year to year needs to pay attention to and carried out studies to reduce the morbidity and mortality of DHF. One of them is by conducting an assessment related to determinant factors. This study aimed to determine the effect of physical and social environmental factors on the incidence of DHF using multilevel analysis.

\section{SUBJECTS AND METHOD \\ 1. Study Design}

This study was an observational analytic study using a case-control design conducted in Bantul Regency, Yogyakarta Special Region, Indonesia, from October to December 2018.

\section{Population and Sample}

The population was people living in Bantul Regency. A total of 250 study subjects were selected using the fix disease sampling method.

\section{Study Variables}

The dependent variable in this study was the incidence of DHF. The independent variables at the individual level were the Maya Index, density figure, household crowding, knowledge, mosquito nests eradication behavior, and the use of mosquito repellents. The independent variable at the village level was the village strata. 


\section{Operational Definition of Variables Dengue Hemorrhagic Fever was a per- son suffering from DHF based on the re- sults of a medical examination. The data scale used a dichotomy with the criteria $\mathrm{O}=$ not suffering from DHF; $1=$ suffering from dengue.}

Maya Index was the presence or absence of potential mosquito breeding habitats by measurement. The data scale was a dichotomy with the criteria $\mathrm{O}=$ low Maya Index; 1= high Maya Index.

Density Figure was a parameter that described the density level of larvae Aedes aegypti and Aedes albopictus based on a set indicator. The data scale was a dichotomy with the criteria $\mathrm{o}=$ low Density Figure; $1=$ high Figure Density.

Household crowding was the ratio between the number of family members living with the house's floor area. The data scale was a dichotomy with the criteria $\mathrm{O}=$ not crowding; $1=$ crowding.

Knowledge was the understanding of study subjects about DHF starting from the etiology, transmission, signs and symptoms, diagnosis, treatment, and efforts to prevent and overcome the disease. The data scale was a dichotomy with the criteria $0=$ high knowledge; $1=$ low knowledge.

Mosquito nests eradication behavior was an activity carried out to eradicate mosquito nests in the environment around the house. The data scale was a dichotomy with the criteria $0=$ good; $1=$ poor.

The habit of using mosquito repellents was an activity carried out to avoid mosquito bites in the form of repellents, mosquito coils, spray, and electricity. The data scale was a dichotomy with the criteria $0=$ use $; 1=$ do not use.

Strata desa siaga was the village status determined by the Bantul District Health Office based on the criteria for the active alert village of the Ministry of Health in the
Minister of Health Decree Number 1,529 of 2010 with the criteria $0=$ pratama; $1=$ madya; $2=$ purnama; $3=$ mandiri.

\section{Study Instruments}

The study instrument used for data collection was a questionnaire about Maya Index, density figure, household crowding, knowledge, mosquito nests eradication behavior, and use of mosquito repellent.

\section{Data Analysis}

Analysis Univariate was conducted to obtain the frequency distribution and percentage characteristics of the study subjects. Bivariate analysis was carried out to analyze the relationship between the independent and dependent variables using Chi-Square and calculation of the Odds Ratio (OR) with 95\% CI and a significance level of $\mathrm{p}<0.050$. Multivariate analysis used multilevel multiple logistic regression analysis with the Intra-class Correlation Coefficient (ICC) value.

\section{Research Ethics}

Ethics approval of the study included the subject of study (informed consent), no name (anonymity), confidentiality (confidentiality), and the approval of ethics (ethical clearance). Ethical clearance had been carried out at the Faculty of Medicine, Sebelas Maret University.

\section{RESULTS}

\section{A. Sample Characteristics}

This study's total subjects were 250 subjects in the Bantul Regency, consisting of 125 DHF patients in the case group and 125 non-DHF subjects in the control group.

Table 1 showed the sample characteristics of the subjects. The majority of the subjects had high Maya Index (51.6\%), lowdensity figure (53.2\%), household crowding (58.0\%), high level of knowledge (50.4\%), poor mosquito nests eradication behavior (52\%), and did not use mosquito repellent (50.8\%). 
Nurkhairani et al./ Multilevel Analysis of Dengue Hemorrhagic Fever

\section{B. Bivariate Analysis}

Table 2 showed the relationship of DHF incidence and determinant factors (Maya Index, density figure, household crowding, knowledge, mosquito nests eradication behavior, and use of mosquito repellent).
There was an effect of Maya Index on the incidence of DHF. Households with a high Maya Index increased the risk of experiencing DHF cases 4.32 times compared to a low Maya Index $(\mathrm{OR}=4.32 ; \mathrm{p}$ $<0.001)$.

Table 1. Sample Characteristics (categorical data)

\begin{tabular}{llcc}
\hline \multicolumn{1}{c}{ Variables } & \multicolumn{1}{c}{ Categories } & Frequency (n) & Percentage (\%) \\
\hline \multirow{2}{*}{ Maya Index } & Low & 121 & 48.4 \\
\multirow{2}{*}{ Density Figure } & High & 129 & 51.6 \\
\multirow{3}{*}{ Household } & Low & 133 & 53.2 \\
& High & 117 & 46.8 \\
Knowledge & Not crowding & 105 & 42.0 \\
\multirow{2}{*}{ Mosquito Nests Eradication } & Crowding & 145 & 58.0 \\
\multirow{2}{*}{ Use of Mosquito Repellent } & High & 126 & 50.4 \\
& Low & 124 & 49.6 \\
& Poor & 120 & 48.0 \\
& Using & 130 & 52.0 \\
& Not using & 123 & 49.2 \\
\hline
\end{tabular}

Table 2. Factors affecting the incidence of DHF (Maya Index, Density Figure, household crowding, knowledge, mosquito nests eradication behavior, and use of mosquito repellent) (Chi-square)

\begin{tabular}{|c|c|c|c|c|c|c|c|c|}
\hline \multirow{3}{*}{ Variables } & \multicolumn{4}{|c|}{ DHF Incidence } & \multirow{2}{*}{\multicolumn{2}{|c|}{ Total }} & \multirow{3}{*}{ OR } & \multirow{3}{*}{$\mathbf{p}$} \\
\hline & \multicolumn{2}{|c|}{ No } & \multicolumn{2}{|c|}{ Yes } & & & & \\
\hline & $n=125$ & $\%$ & $n=125$ & $\%$ & $n=250$ & $\%$ & & \\
\hline \multicolumn{9}{|l|}{ Maya Index } \\
\hline Low & 86 & 68.8 & 35 & 28.0 & 121 & 48.4 & $4 \cdot 32$ & $<0.001$ \\
\hline High & 39 & 31.2 & 90 & 72.0 & 129 & 51.6 & & \\
\hline \multicolumn{9}{|c|}{ Density Figure } \\
\hline Low & 88 & 70.4 & 45 & 36.0 & 133 & 53.2 & 3.46 & $<0.001$ \\
\hline High & 37 & 29.6 & 80 & 64.0 & 117 & 46.8 & & \\
\hline \multicolumn{9}{|l|}{ Households } \\
\hline Not crowding & 64 & 51.2 & 41 & 32.8 & 105 & 42.0 & 1.90 & 0.059 \\
\hline Crowding & 61 & 48.8 & 84 & 67.2 & 145 & 58.0 & & \\
\hline \multicolumn{9}{|l|}{ Knowledge } \\
\hline High & 82 & 65.6 & 44 & 35.2 & 126 & 50.4 & 2.80 & 0.002 \\
\hline Low & 43 & 34.4 & 81 & 64.8 & 124 & 49.6 & & \\
\hline \multicolumn{9}{|c|}{$\begin{array}{l}\text { Mosquito Nests } \\
\text { Eradication }\end{array}$} \\
\hline Good & 72 & 57.6 & 48 & 38.4 & 120 & 48.0 & 2.73 & 0.003 \\
\hline Poor & 53 & 42.4 & 77 & 61.6 & 130 & 52.0 & & \\
\hline \multicolumn{9}{|l|}{ Mosquito } \\
\hline \multicolumn{9}{|l|}{ Repellent } \\
\hline Using & 79 & 63.2 & 44 & 35.2 & 123 & 49.2 & 2.48 & 0.007 \\
\hline Not using & 46 & 36.8 & 81 & 64.8 & 127 & 50.8 & & \\
\hline
\end{tabular}


There was an effect of the density figure on the incidence of DHF. Households with high-density figure increased the risk of experiencing DHF cases 3.46 times compared to low-density figure $(\mathrm{OR}=3.46 ; \mathrm{p}$ $<0.001)$.

There was an effect of household crowding on the incidence of DHF. High household crowding increased the risk of experiencing DHF cases 1.90 times compared to low household crowding $(\mathrm{OR}=$ 1.90; $\mathrm{p}<0.001$ ).

There was an effect of knowledge on the incidence of DHF. Household members with a low level of knowledge increased the risk of experiencing DHF 2.80 times compared to knowledge high $(\mathrm{OR}=2.80 ; \mathrm{p}=$ 0.002).

There was an effect of mosquito nests eradication on the incidence of DHF. Households with poor mosquito nests eradication behavior increased the risk of experiencing DHF 2.73 times compared to high knowledge $(\mathrm{OR}=2.73 ; \mathrm{p}=0.003)$.

There was an effect of using mosquito repellent on the incidence of dengue fever. Household members who did not use mosquito repellent increased the risk of experiencing DHF 2.48 times compared to using mosquito repellent $(\mathrm{OR}=2.48 ; \mathrm{p}=$ 0.007).

\section{Multilevel Multiple Logistic Re- gression Analysis}

Multilevel multiple logistic regression analysis was conducted to discover the effect of more than one independent variables toward dependent variables in individual level, also to calculate the effect of village strata in higher level toward the dependent variable. Independent variables that would be included in multivariate model were Maya Index, density figure, household crowding, knowledge, mosquito nests eradication behavior, and use of mosquito repellent. The results of multivariate analysis would be presented in Table 3 .

\section{Effect of Maya Index on DHF in- cidence}

There was an effect of Maya Index on the incidence of DHF. Household members with high Maya Index had a risk of being infected with dengue 5.04 times compared to low Maya Index $(\mathrm{OR}=5.04 ; 95 \% \mathrm{CI}=$ 2.38 to 10.69 ; $\mathrm{p}<0.001)$.

\section{Effect of density figure on DHF incidence}

The risk of dengue infection also increased in household members with a high density figure. Household members with a high density figure had 4.01 times risk of becoming infected with dengue compared to low density figure $(\mathrm{OR}=4.01 ; 95 \% \mathrm{CI}=1.91$ to 8.44 ; $\mathrm{p}<0.001)$.

\section{Effect of household crowding on DHF incidence}

The risk of dengue infection increased in high household crowding. Family members with high household crowding had a risk of dengue infection 1.90 times compared to low household crowding $(\mathrm{OR}=1.90 ; 95 \%$ $\mathrm{CI}=0.91$ to $3.95 ; \mathrm{p}=0.087$ ).

\section{Effect of knowledge on DHF incidence}

The risk of dengue infection increased in household member with low level of knowledge. Study subjects with a low level of knowledge had a risk of becoming infected with dengue fever 2.94 times compared to high level of knowledge (OR= 2.94; $95 \% \mathrm{CI}=1.41$ to $6.12 ; \mathrm{p}=0.004)$.

\section{Effect of mosquito nests eradi- cation behavior on DHF incidence}

The risk of dengue infection increased in household member with poor mosquito nests eradication behavior. Household members with poor mosquito nests eradication behavior had 3.09 times the risk of DHF infection than those with good mos- 
quito nests eradication behavior (OR= 3.09 ; $95 \% \mathrm{CI}=1.47$ to $6.49 ; \mathrm{p}=0.003$ ).

\section{Effect of mosquito repellent on DHF incidence}

The risk of dengue infection increased in household member who did not use mosquito repellent. Household members who did not use mosquito repellent had 3.06 times the risk of DHF infection than those who used mosquito repellent $(\mathrm{OR}=3.06$; 95\% $\mathrm{CI}=1.45$ to $6.45 ; \mathrm{p}=0.003$ ).

Multilevel multiple logistic regression analysis showed ICC $=17 \cdot 34 \%$. it indicated that $17.34 \%$ of the variation in the incidence of DHF was caused by contextual factors located in the village level. The rest $82.66 \%$ was on the individual factors. LR test vs. $\log$ regression showed $\mathrm{p}=0.008$. it indicated a statistically significant difference between the estimation results between multiple logistic regression analysis without multilevel versus multilevel. In other words, there was a significant contextual effect at the village level on the DHF incidence.

Table 3. Multilevel multiple logistic regression analysis of factors affecting the incidence of DHF (Maya Index, density figure, household crowding, knowledge, mosquito nests eradication behavior, and use of mosquito repellent)

\begin{tabular}{|c|c|c|c|c|}
\hline \multirow{2}{*}{ DHF Incidence } & \multirow{2}{*}{$\mathbf{O R}$} & \multicolumn{2}{|c|}{ 95\% CI } & \multirow{2}{*}{$\mathbf{P}$} \\
\hline & & Lower limit & Upper limit & \\
\hline \multicolumn{5}{|l|}{ Fixed Effect } \\
\hline Maya Index (high) & 5.04 & 2.38 & 10.69 & $<0.001$ \\
\hline Density Figure (high) & 4.01 & 1.91 & 8.44 & $<0.001$ \\
\hline Household Crowding (high) & 1.90 & 0.91 & 3.95 & 0.087 \\
\hline Knowledge (low) & 2.94 & 1.41 & 6.12 & 0.004 \\
\hline Mosquito nests eradication behavior (poor) & 3.09 & 1.47 & 6.49 & 0.003 \\
\hline Use of mosquito repellent (no) & 3.06 & 1.45 & 6.45 & 0.003 \\
\hline \multicolumn{5}{|l|}{ Random Effect } \\
\hline Village strata (constanta) & 0.69 & 0.18 & 2.65 & \\
\hline \multicolumn{5}{|l|}{$\mathrm{N}$ observation $=250$} \\
\hline \multicolumn{5}{|l|}{ Log likelihood $=-106.01$} \\
\hline \multicolumn{5}{|l|}{ LR test vs. logistic regression, $p=0.080$} \\
\hline $\mathrm{ICC}=17.34 \%$ & & & & \\
\hline
\end{tabular}

\section{DISCUSSION}

\section{Effect of Maya Index on DHF in- cidence}

This study showed a significant effect between Maya Index and DHF incidence. Household members with high Maya Index had a risk of being infected with DHF 5.04 times compared to low Maya Index. This was in line with the results of Sona's (2019) study, which stated that Maya index had an effect on the incidence of DHF in the area.

Maya Index is a new indicator to identify the amount of risk as breeding mosquitoes Aedes site for in a high-risk residential or community environment. The basis for assessing the magnitude of the risk is the area's cleanliness status and the availability of places that might be potential breeding for mosquitoes (Lozano et al, 2002).

The existence of water-filled unused containers was related to increasing the vector Aedes aegypti, as the more available breeding site for Aedes aegypti mosquito. It makes easier for vectors Aedes aegypti to reproduce, so that the mosquito population will continue to increase (Narmala, 2019). Thus, the potential for an increase in dengue cases also increases. 


\section{Effect of density figure on DHF incidence}

This study indicated a significant effect between density figure and DHF incidence. The risk of dengue infection increases in household members with a high density figure by 4.01 times compared to a low density figure. These results were in line with the results of research by Sorisi and Pijoh (2017), which was conducted in dengue-endemic areas with 100 households. That study indicated the density figure in the DHF endemic area (Singkil District) falls into the high category.

Density Figure was an indicator that had been established by WHO to assess the risk of dengue transmission in an area based on the calculation of the indicators of the house index, container index, and Breteau index.

\section{Effect of household crowding on DHF incidence}

This study showed a significant effect between household crowding and the incidence of dengue fever. Family members with high occupancy rates had a risk of infection with dengue fever 1.90 times compared to those with low occupancy densities. This study was in line with the research results by Kaeng et al. (2020), which illustrated that residential density affected dengue fever incidence $(\mathrm{p}=0.031)$.

Another study that described similar results was research conducted by Prastiani and Prasasti (2017). One of the factors that influence the incidence of DHF was the density of the house occupancy (<0.001). These results were based on research on 64 houses where positive larvae Aedes aegypti. The majority of respondents had poor occupancy density = 41 subjects. However, 23 houses with good occupancy density also found larvae Aedes aegypti.

Occupancy density was one of the social factors that influence disease inci- dence. Occupancy density affected human movement.

\section{Effect of knowledge on DHF inci- dence}

This study showed a significant effect between knowledge and the incidence of DHF. Family members with a low level of knowledge about DHF had a risk of infected with DHF 2.94 times compared to high level of knowledge. This study was in line with the results of study by Prastiani and Prasasti (2017), which illustrated that knowledge affected the incidence of DHF ( $p$ $<0.001$ ).

Knowledge is part of the determinants of social factors in disease incidence, includeing Dengue Fever (Delmelle et al., 2016). According to (Gyawali et al., 2016), the level of knowledge, attitudes, and behavior of the community played a very important role in determining the outcome of the implemented Dengue Fever control program. Although many people may have heard about Dengue Fever, most of them are not aware of the disease's symptoms and do not have adequate knowledge on prevention or control.

\section{Effect of mosquito nests eradica- tion behavior on DHF incidence}

This study showed an effect of mosquito nests eradication behavior on DHF incidence. Household members with poor mosquito nests eradication behavior had a risk of infection with dengue fever 3.09 compared to good behavior one.

This study's results were in line with the research results conducted by Priesley et al. (2018), with 28 subjects in the case group and 56 in the control group. It showed that subjects with poor mosquito nests eradication behavior had 5.84 times the risk of being infected with DHF.

Dengue mosquito nest eradication is an activity to eradicate the eggs, larvae, and cocoons of dengue transmitting mosquitoes 
(Aedes aegypti) in their breeding sites. This activity aims to control the mosquito population Aedes aegypti to prevent or reduce dengue transmission. The targets of eradicating dengue mosquito nets are all breeding sites for dengue-transmitting mosquitoes, including water reservoirs for daily use, water reservoirs not for daily use, and natural water reservoirs.

\section{Effect of Mosquito repellent on DHF incidence}

The results showed that there was an effect of using mosquito repellent on the incidence of DHF. Household members who did not use mosquito repellents a risk of infection with dengue fever 33.06 times compared to those who use mosquito repellents. These results were in line with the research results conducted by Sandra, et al (2019). It showed that household members who did not use mosquito repellent had 4.29 times the risk of dengue fever than those who use them.

The use of mosquito repellent is one of the individual efforts to prevent DHF. Commonly used mosquito repellent in households is spray or aerosol, combustible, and electric as personal protection against mosquito bites.

Likewise, with topical mosquito repellent, there is natural and chemical repellent. Pure oil from plant extracts is the main ingredient of natural repellents such as lemongrass oil, citron oil, and neem oil. Meanwhile, chemical types such as DEET (Diethylm-Toluamide) can protect against Aedes aegypti mosquitoes, Aedes albopictus and Anopheles mosquitoes for several hours and other ingredients such as Oil of Lemon Eucalyptus (OLE), Para-methane and others.

\section{AUTHOR CONTRIBUTION}

Nurkhairani was the main researcher who selected topics, searched, and collected the research data. Setyo Sri Rahardjo and Bhisma Murti played a role in analyzing data and reviewing research documents.

\section{CONFLICT OF INTEREST}

There is no conflict of interest.

\section{FUNDING AND SPONSORSHIP}

This study used personal funds from the main researcher.

\section{ACKNOWLEDGEMENT}

The authors would like to express their gratitude to the Bantul district government and all the research subjects who have provided the opportunity to do research.

\section{REFERENCE}

Brady OJ, Gething PW, Bhatt S, Messina JP, Brownstein JS, Hoen AG, Moyes $\mathrm{CL}$, et al. (2012). Refining the global spatial limits of dengue virus transmission by evidence-based consensus. PLoS Neglected Tropical Diseases. 6(8): e176o. https://doi.org/10.1371/journal.pntd.ooo176o.

Delmelle E, Hagenlocher M, Kienberger S, Casas I (2016). A spatial model of socioeconomic and environmental determinants of dengue fever in Cali, Colombia. Acta Tropica. 164: 169176. https://doi.org/10.1016/j.actatropica.2016.08.028.

Gubler DJ (1998). Dengue and dengue hemorrhagic fever. Clin Microbiol Rev. 11(3): 480-496. https://doi.org/10.1128/CMR.11.3.480.

Huang CC, Hsu CC, Guo HR, Su SB, Lin HJ (2017). Dengue fever mortality score: A novel decision rule to predict death from dengue fever. J Infect. 75(6): 532-540. https://doi.org/10.1016/j.jinf.2017.09.014.

Kaeng LW, Finny W, Oksfriani JS (2020). Preventive behavior and occupancy 
overcrowding with dengue hemorrhagic fever. Indones $\mathrm{J}$ Public Health Community Med. 1(3): 1-6. https://ejournal.unsrat.ac.id/index.php/ijphc $\mathrm{m} /$ article/view/28834/28590.

Narmala YA, Azizah R (2017). Maya index and the density of Aedes aegypti larvae between Tegalrejo village and Krajan Kidul Nanggungan Village, Pacitan. Int J Public Health. 14(2): 199-209. http://dx.doi.org/10.20473/ijph.v14i2.2019.199-209.

Priesley F, Mohammad R, Selfi RR (2018). The relationship of mosquito nest eradication behavior with closing, draining and recycling plus (PSN M Plus) on dengue hemorrhagic fever (DBD) in Andalas Village. Andalas Health J. 7(1): 125-130. https://doi.org/10.25077/jka.v7i1.790.

Prastiani I, Corie IP (2017). Relationship between temperature, density residential, knowledge, attitude with density of larvae in Sub District Gunung Anyar, Surabaya. J Environ Health. 9(1). http://dx.doi.org/10.20473/jkl.voi1.2017.1-10.

Sandra T, Muchlis AUS, Suhartono, Martini Suharyo H (2019). Factors influencing the incidence of dengue hemorrhagic fever in children aged 6-12 years in
Tembalang District. J Community Health Epidemiol. 4(1): 1-10. https://doi.org/10.14710/jekk.v4i1.4423.

Sayavong C, Chompikul J, Wongsawass S, Rattanapan C (2015). Knowledge, attitudes and preventive behaviors related to dengue vector breeding control measures among adults in communities of Vientiane, capital of the Lao PDR. J Infect Public Health. 8(5): 466-473. https://doi.org/10.1016/j.jiph.2015.03.00

Sona B, Emantis RMK, Tugiyono (2019). Maya index analysis of dengue fever vector in East Metro Sub-District Lampung Province Indonesia. J Sci Experiments Biodiversity. 6(1): 1-7. http://dx.doi.org/10.23960\%2Fj_bek h.v6i1.2347.

Sorisi AM, Victor DP (2017). Larval density of Aedes spp. in residential areas of Singkil District, Manado City, Indonesia. Trop Med J. 4(1): 43-47. https://doi.org/10.22146/tmj.37181.

World Health Organization. (2012b). Global strategy for dengue prevention and control, 2012-2020. Geneva, Switzerland: World Health Organization. Retrieved from http://apps.who.int/iris/bitstream/10665/75303/ 1/9789241504034_eng.pdf. 